\title{
Emotional Organization Strategies for Educational Counselors in Government Schools and its Relationship to Some Variables
}

\author{
Areen Mohammed Alghzewat Alkhawaldeh ${ }^{1}$ \\ ${ }^{1}$ Department of Counseling and Mental Health, International Islamic Science University, Amman, Jordan \\ Correspondence: Areen Mohammed Alghzewat Alkhawaldeh, Department of Counseling and Mental Health, \\ International Islamic Science University, Amman, Jordan.
}

Received: February 25, 2020

Accepted: April 17, 2020

Online Published: December 31, 2020

doi:10.5539/mas.v15n1p63

URL: https://doi.org/10.5539/mas.v15n1p63

\begin{abstract}
This study aimed to identify the level of emotional organization strategies among educational counselors in government schools according to the variable (gender and years of experience), and the study sample was chosen randomly, as the sample reached (93) female and male counselors, of whom (41) were male and (52) female counselors, the researcher used the scale of the emotional organization strategies, which were developed for the purposes of this study, where the results showed that the level of the emotional organization strategies was "average" among the study sample individuals on the scale as a whole and the sub-dimensions, as the levels of emotional organization as a whole are higher for males as well as for those with more than ten years of experience and in the light of the results revealed by the study, the researcher recommends the need to take care of the counselors by exposing them to training guidance programs to develop emotional organization strategies that increase their professional and self-efficacy to face professional and life pressures.
\end{abstract}

Keywords: emotional organization strategies, educational counselors, schools

\section{Introduction}

Emotions play a fundamental role in our daily lives. They are considered vital aspects closely related to the personality, behavior, and thinking of individuals. As agitation is a complex and permanent emotional state, and it is an internal state that is categorized within specific epistemological aspects, sensations, reactions, and particular expressive behavior (Al-Zuhaimi, 2011).

The process of organizing personal emotions is a specific structure that indicates the personal context in which his feelings are organized by others (Hofmann, 2014). And despite the many attempts of scientists to study emotional organization, not much is known about managing personal emotions (for example, the methods people use to organize their feelings through their dealings with others). (Hofer, 2006) added that what begins as an organization of basic physiological needs through expressed feelings is gradually becoming a process of organizing feelings. And the strategies of emotional organization occupy great importance in the stages of the lives of individuals because they are linked to their mental health, due to the nature of the emotional changes represented by sharpness, volatility, and contradiction, which force the counselors to try several ways to organize it (Salloum, 2015).

And the emotional organization studies contributed to pointing out a strong relationship between emotional organization strategies and mental health, which confirmed that the difficulty in using the appropriate emotional organization strategies appears as a cause or result of many mental health disorders (Arndt \& Fujiwara, 2014).

The researcher finds that the concept of emotional organization strategies has focused on two fundamental concepts, the social aspect and its effect on the formation of emotions and their diversity through social interactions and social growth.

The second concept regarding the emotional organization at the individual's internal level is affected by the basic cognitive processes and learning experiences. Therefore it is necessary to understand the fundamental link between the cognitive and social aspects in interpreting the emotional organization process. 


\section{The study Problem}

The problem of study appears in the sense that the emotional organization is (need challenge) according to the expression (Golman, 1999), in general, and in particular, the counselor learns to organize his emotions through years in the field of advisory work, as the counselor is more likely to appear cases of anxiety, depression and borderline personality disorder. (Berking \& Wupperman, 2012), as the counselor reaches stress and anxiety as a feature and negative self-talk (Abel et al., 2012) and in most of the time, emotional organization strategies are closely related to mental health (Arndt \& Fujiwara, 2014).

The fifth diagnostic manual confirms this for mental disorders that most mental disorders included a defect in the regulation of affective and emotional situations, and it is associated with many psychological problems such as anxiety, depression, and borderline personality disorder (Berking \& Whitely, 2014).

At the beginning of their career, the adviser faces anxiety, fear, and guilt during career development, and advisers often become more self-aware and more self-confident over time (Stoltenberg \& McNeill, 2009).

The current study within this concept is necessary for the adviser to help him reveal his emotional organization levels, which may affect the counselor's self and professional competence. This study benefits counselors by assisting them in dealing with counter-reaction reactions, increasing general emotional intelligence, and exploring the need for personal counseling and promoting psychological well-being, (Berry, Hansenne, Quoidbach, \& Mikolajczak, 2010) which may affect the adviser's self and professional competence. This study benefits advisers by helping them deal with counter-reaction reactions, increasing general emotional intelligence, exploring the need for personal counseling, and promoting psychological well-being (Berry, Hansenne, Quoidbach, \& Mikolajczak, 2010). It is an essential element in the advisers' mental health, directing them towards good handling of the emotions, adopting appropriate methods to organize and express them, and alleviating mental disorders such as depression and anxiety (Prikhidko \& Swank, 2018).

\section{Study Questions}

This study starts with the following two questions:

1) What is the level of emotional organization of counselors in schools in the capital Amman governorate?

2) Are there statistically significant differences in the average degree of emotional organization among school counselors in Amman governorate due to the variable (gender, number of years of experience)?

\subsection{Objectives of the Study}

The current study aims to identify the level of emotional organization of the educational counselor through:

1) Identify the level of emotional organization of educational counselors according to the variables (gender and number of years of experience)

2) Disclosure of the differences in the degree of dimensions of the emotional organization strategies of educational counselors in government schools in the capital Amman, attributable to the variables (gender and number of years of experience).

\subsection{The Importance of the Study}

The importance of the study lies in the nature of the study, and the study seeks to know the level of emotional organization among educational counselors in schools, where the importance of the study in theory or practice includes the following:

\subsubsection{Theoretical Importance}

1) It provides the Arab library with more about the strategies of emotional organization among educational counselors in schools, where studies are still limited in scope, whether at the local environment or the Arab level in the study of the counselor's emotional organization.

2) Identify the counselor.

3) 's personality strengths and weaknesses, thus following the best ways to enhance his positive emotional aspects and improve his psychological compatibility.

4) Enrich the Arab Library with tools for relatively recent variables concerning the emotional organization, as the researcher translated an instrument for measuring emotional organization after its translation, arbitration, and suitability for the study environment. 
5) This study may help in further studies in educational counselors' emotional organization to support this group and achieve the academic guidance process's desired goals.

\subsubsection{Applied Importance}

1) The current study can employ the emotional regulation scale in more studies by identifying the levels of emotional organization of educational counselors, developing their psychological compatibility and satisfaction with their performance, and developing plans to advance them.

2) Through this study's results, it is possible to make recommendations in this field to those interested in studying the counselors' emotional organization to prepare counseling programs for those with low levels of emotional organization and satisfaction with their performance.

3) The importance also stems from the fact that emotional organization can be developed. The researcher finds that this study can improve or make adjustments to the training programs directed to the counselor to contribute to the promotion and development of this among educational counselors.

\subsection{Study Terms and Its Procedural Concepts}

\section{Emotional Regulation:}

Gross defined passive organization strategies as the methods one uses to influence emotional response levels (Gross, 2002, p.11). The following dimensions are represented in the current study with the following:

- Re-focus positive: focuses on the positive aspects instead of thinking about the situation itself.

- Social support: It employs positive social interactions to reduce anxiety and stress.

- Receptiveness: The individual accepts his emotions related to the circumstances around him.

- Emotional awareness: Distinguish and recognize feelings.

- Procedurally defined: The degree to which the counselor obtains the scale of the emotional organization strategies used in the research, and is measured by the total degree.

Educational counselor: It is every person who provides educational services, taking into account the psychological, social, and professional aspects of the student, so that it aims to help him understand himself and his capabilities and self and environmental capabilities, and use them to achieve his goals and in line with these self-capabilities and the environment (Abu Hammad, 2006).

Educational counselor Procedurally: "As the person holding a bachelor's degree or a master's degree in psychology or psychological counseling, he provides a professional human service to help students solve their problems, And in government schools affiliated with the Jordanian Ministry of Education."

\subsection{Study Limits}

The results of this study are determined in terms of generalizability by the following determinants:

Objective limits: This study defines the scale of emotional organization among educational counselors in government schools in the capital, Amman, and it consists of (20) items within four dimensions, namely: (Positive refocus, social support, acceptance, emotional awareness).

Human limits: The researcher conducted the study on a sample of government school counselors in the Amman Governorate.

Spatial limits: The study tool was applied to educational counselors in the directorates of education affiliated to Amman Governorate (Capital District Education Directorate, University District, Marka District, Wadi Al-Seer, Qweismeh).

Time limits: The researcher conducted the study during the first semester of the academic year (2019-2020).

\section{Emotional organization:}

The individual experiences various emotions in each situation, and this requires flexibility and the ability to change responses according to those situations. To remain able to continue in daily life, he seeks to understand how to deal with the emotional problems he faces and communicate his feelings through the process of organizing emotions that he feels and informs, and to influence these emotional experiences, the timing of their occurrence and ways to live with and express it. The individual can control his emotions and respond using the means and strategies (internal and external) associated with emotional understanding to adapt to life's requirements (Afana, 2018). 
Emotion is a complex emotional state accompanied by different physical and physiological activity accompanied by external movement or verbal changes. The intensity of tension or emotion increases when the individual is exposed to sudden stimuli that he has not prepared for with a specific type of response, as defined by (Greenberg). This subjective experience involves interpreting the meaning and interacting with the environment (Greenberg, 2004). Emotional Organizing Strategies (Gross, Bunge, \& Mauss, 2007) point to a person's ability to manage an emotional experience effectively, where individuals use organization strategies to boost their mood and deal with a variety of feelings, including anger, anxiety, and guilt. Emotional regulation strategies may be automatic or consciously or deliberately controlled.

Cross believes that "emotional organization" refers to behaviors and strategies, whether subconscious or automatically, that modify, prevent, and improve emotional experiences and expressions. All emotional contents, such as subjective feelings, behaviors, and physiological responses, are changeable or maintained in the emotional organization process. And it consciously or unconsciously. "Gross" also believes that the standard form of emotion contains the agreed principles and represents common points of interest between researchers and those who specialize in the subject of emotions and provides a sequential and organized model. As the response begins with a situation related to the environment surrounding the individual, often external or physically, attention is paid to dealing with the situation in multiple ways according to this evaluation and goals. It raises an assessment of the formation of the individual's perception and appreciation of this situation among other stimuli, the extent of familiarity of the situation with the individual, and its association level.

Emotional responses arise and include changes in multi-physiological response systems and subjective and behavioral experience, and these responses often change the attitude that triggered the response (Afaneh, 2018). The individual adjusts his emotional states that he experiences using emotional organization processes by maintaining, modifying, or changing the occurrence, intensity, or duration of internal states of feeling and the physiological processes related to emotion and behavior (Eisenberg, 2001)).

The emotional organization contains many strategies and interrelated organizational processes to achieve the goal through the processes of modifying the extracted emotions, and it refers to the internal emotional organization processes that are carried out by the individual himself (emotion regulation) and the external processes of the emotional organization carried out by others (Koole, 2009). Emotional regulation includes the multiple types (negative and positive) that are regulated, and several studies have referred to the emotional organization processes used to organize negative emotions such as anger, fear, and sadness; the emotional organization also contributes to reducing, increasing, or maintaining the intensity of the emotional responses based on the goals of the individual. (Cole, Martin, \& Dennis, 2004)

Gratz \& Roemer (2004) believes that effective emotional regulation includes the following points:

1) Emotional awareness and clarity.

2) Accept emotional responses.

3) To have the ability to control motivation and act according to the desired goal through negative emotional experiences.

4) To have the ability to use emotional organization strategies in various situations flexibly and appropriately to modify emotional responses to achieve the specified goal.

\section{Emotional organization of counselors}

Emotion is a component of influencing and shaping behavior and beliefs and is a broader concept that includes stress and mood (Scherer, 2005). Additionally, agitation is a multifaceted, whole-body phenomenon that includes subjective experience, cognitive assessment, and sensory nervous system response (Mauss, Bunge, \& Gross, 2007). However, there is little research studying the emotional experiences of counselors (Cook, 2009). Counselors can illustrate emotional organization strategies by directing emotion in two directions:

1) Directing emotion toward themselves:

The counselor may direct these feelings and emotions to himself or the person seeking counseling. Where the emotions and feelings towards the same counselor through feeling guilty? So, counselors may blame themselves for doing something, or even thinking and feeling, something considered inappropriate according to the counseling profession's social and ethical standards. For example, the counselor may believe that he is not good enough to help the person seeking counseling (Parker \& Thomas, 2009) and thus generate feelings of anxiety, stress, and anger directed towards himself or others (Cook, 2009). Many emotions (such as guilt, anger, and anxiety) increase the level of fatigue, reduce the counselor's professionalism, and weaken the ethical principles necessary for the counselor's work (Prikhidko \& Swank, 2018). 
(Houseknecht, Su, \& Prirkhidko, 2017) added that the most frequent reactions of counselors were (a) increased caution in providing guidance, counseling, (b) Increased consultation with colleagues (c) Strong feelings of guilt along with other emotions such as sadness, depression, loss when he declares that he is unable to help the counselors or that their guiding work is not enough with the counselors.

2) Directing emotion towards people who seek counseling:

Among the most important emotions that may appear at the counselor towards the people who seek counseling are anger and anxiety, and anger seems toward the person who seeks counseling if a lack of confidence dominates the counseling relationship or if the person who is seeking counseling transmits feelings of anger with the counselor, As the counselor begins to feel confused about his feelings of anger and how to express it (Prikhidko \& Swank, 2018). As for emotional anxiety, it has a social origin (Abel et al., 2012). It arises as a result of communication between the counselor and the people who seek counseling. As a result of indifferent or degrading reactions from the person seeking counseling, which increases stress, psychological pressure, and physical signs such as sweating, shaking, and redness of the face, especially for junior counselors (Prikhidko \& Swank, 2018).

The researcher believes that the emotional organization of the counselors is evident in two aspects. The first aspect is closely related to the ideas and beliefs that the counselor forms about himself through the general perception of the counselor and his psychological, cognitive, and behavioral characteristics required of him. Which leads the counselor to employ the strategies of the emotional organization to control his different emotions, which he passes through different experiences; the other side is evident through the development of emotional organization strategies to conform to the requirements of the profession during periods of university study, practical experiences and training in the counseling profession.

\section{Explanatory theory of emotional organization:}

\section{Gross theory of emotional organization:}

Gross (2002) believes that emotional organization is a Subconscious and unconscious strategy that an individual uses to increase, decrease, or maintain one or more components of an emotional response. He defines it with three components: the experience component, and it includes the subjective feelings of the individual according to his life experiences, and the behavioral component includes behavioral responses, and the physiological component includes physiological responses such as heartbeat, blood pressure, hair, and skin stiffness. Gross also believes that emotional organization enables the individual to use a set of strategies that he lists in the context of two types:

\section{1) Pre-focus strategy:}

This strategy includes the individual's operations before the emotional situation occurs and the generation of emotional responses altogether. (For example, when the individual hears that a friend spoke about him in his absence negatively, before showing the emotional response, the individual assesses the situation and may feel sad rather than feeling angry towards his friend). It distinguishes between four types that can be applied in different conditions of the process of triggering emotion, namely: (1) Selection of the position: In which the individual chooses from two or more conditions to be in one position. (2) Situation modification: It is the position in which the individual has more than a different level of emotionalism. (3) Distributing or spreading attention: This refers to the process of changing awareness of the situation, such as when an individual closes his eyes when he watches a shooting process. (4) cognitive change: refers to the process of selecting a cognitive meaning for the event or situation, and cognitive reassessment means that the individual reassesses the cognitive of the situation to extract the possible emotion from that situation and reduce its impact.

\section{2) Response Focus Strategy:}

This strategy represents the processes that the individual performs after the emotional response has occurred, and when the emotion is just standing up, for example: When an individual is at a party and meets someone he does not like, this person paints a fake smile on his face while he is uncomfortable with him. This strategy has one type that Gross calls the response modification and is applied after an emotional response has occurred. It is called suppression; here, the individual stops moving on expressing his emotions in the situation or hides the signs of emotional expression, and in many cases, the purpose of this strategy is to submit to the order of the group or to obey the position or socializing. 


\subsection{Previous Studies}

In a study (Abel et al., 2012), The level of emotional stress and management of anxiety and coping techniques were examined by (101) graduate students in the specialty of counseling, where the study included independent factors such as (ethnic groups and gender), where the percentage of females (79\%) and (21\%) were males. Statistically, significant differences appeared in (6) of the seven dependent variables (emotional stress level and response to anxiety based on positive and negative self-talk and general psychological anxiety, anxiety status, and trait). The results were that the treatment group and training in emotional stress management strategies performed better in dealing with stress than the dependent group.

(Cook, 2009) tried with his study to reveal the emotional organization strategies of the counselors and evaluate them through individual interviews and records, and to use the scale 1 - the emotional organization strategies (IRT) 2 - the emotional organization difficulties scale (DERS), the study aimed to compare the extent to which counselors employ strategies of the emotional organization, assess emotional development, and occupational risk assessment, including self-harm by using inappropriate emotions and their reflection on the counselor's mental health, harm to the counselor, and harm to the profession, through an experiment with a full range of emotions, the ability to modify emotions, and the ability to display emotions appropriately, and the ability to respond effectively to other people's emotions. The study results revealed no significant differences between the counselors' responses to the scale before the training program and after the training program. In contrast, counselors need a more extended period than the program's duration to better employ more appropriate strategies to use emotions appropriate to the profession.

In a study (Ramadan, 2012) entitled Emotional equilibrium among the counselors, where the study sample consisted of (100) counselors according to the specialty variable (psychology, counseling, sociology) and gender, the researcher used the emotional balance scale prepared by the researcher, and the results of the study came out that the level of emotional balance among the counselors was at an average level. And there are no differences between male and female counselors in the level of emotional equilibrium, and there are statistically significant differences in the level of emotional balance in favor of the specialty of psychology and then counseling.

According to the researcher's knowledge, the literature survey did not show any Arab study that examined the level of emotional organization strategies among educational counselors in government schools. However, a few Arab studies examined the emotional organization of university and school students. It will be addressed as studies related to the study's subject; the following is a review of the most important of these studies, which were conducted in different educational environments.

A study by Afana, Muhammad (2018) showed that the most common emotional organization strategies among university students' study sample are the rumination strategy with a rate of (71.7). At the same time, the intimidation strategy was less prevalent (65.2). The study (Salloum, 2015) concluded that there is no relationship between rumination strategy, social participation, and problem-solving for the two-stage students. There is also a statistically significant relationship between the suppression and acceptance strategies and the total score on the scale of problem-solving for undergraduate students. As for a study (Abdel Hadi, 2012) entitled Common cognitive strategies to regulate emotions among a sample of Jordanian university students in light of the variables of gender, university, and specialization to reveal the cognitive processes for organizing emotions among a sample of the University of Jordan students, in light of the variables of gender, university, and specialization to reveal the cognitive strategies for organizing emotions among a sample of the University of Jordan students, Al-Ahliyya Amman University, and the Arab Open University, Jordan Branch.

The study sample consisted of (383) male and female students from the specializations of administration, computer, English, and education. And the Arabized and legalized picture was applied to the Jordanian environment for the scale of cognitive strategies, which consists of (56) paragraphs that measure cognitive strategies in regulating emotions. The study results showed that the strategy of religious ideas ranked first as the most used strategy by university students, followed by analyzing emotions and attitude, growth and reshaping, and the least used strategy to reduce the topic's importance. The study also found statistically significant differences at the level of (0.05) and less among students in cognitive strategies according to gender variables (male/female) and academic and university level. Females are more used to strategies of religious ideas, comparison with past events, and reality testing. And students of the first level of study use the strategy of self-blame and criticism higher than students of the second level and the use of students of the third level for this strategy more than students of the fourth level. As for accepting the situation, the first level students showed a higher acceptance of the position than the third and fourth level students. Al-Ahliyya Amman University students showed a higher level of self-blame than the University of Jordan and the Arab Open University 
students. They, in turn, demonstrated a higher level of religious ideas to organize their negative emotions. Simultaneously, there are no significant differences between students in strategies to regulate emotions according to the variable of specialization.

The study (Aldao et al., 2010) showed a significant impact size of rumination; also, after studying the relationship between each emotional regulation strategy with all four groups of mental disorders (anxiety, depression, eating disorders, and drug use disorders), the study concluded that the interfering disorders have a strong correlation with emotional organization strategies higher than that of outward-oriented disorders.

A study of (Kown et al., 2013) also showed that Korean students were more used to ruminant strategy than American students, while Americans were more suppressive of anger than Koreans; it also showed that in both cultures, females are more used to both types of strategies (rumination and suppression). In a study conducted by (Hu et al., 2014), the results concluded that there is a positive correlation between cognitive reassessment and positive mental health indicators. And the presence of a negative relationship between suppression and positive mental health indicators, and a strong correlation between the suppression and negative indicators of mental health, where the study (Afaneh, 2018; Salloum, 2015) aimed to identify the emotional organization of university students and to identify the levels of using the emotional organization strategies as well as the levels of problem-solving.

While the study (Hu et al., 2014) aimed to examine the relationship between emotional regulation strategies (suppression and emotional reorganization) and mental health (using the measure of satisfaction with life, depression, anxiety, negative and positive emotions). A study (Kown et al., 2013) aimed to examine the relationship between the emotional organization strategy and symptoms of depression among college students from two different cultures. As for the study (Aldao et al., 2010), it aimed to identify the relationships between six strategies of the emotional organization (acceptance, avoidance, problem-solving, cognitive reassessment, rumination, suppression) and their relationship with the symptoms of four psychological disorders (anxiety, depression, eating disorders, and drug use disorders).

As for the sample, previous studies were limited to school and university students. The researcher's briefing in prior studies showed that most studies covered the descriptive approach, analytically and relationally, concerning the curriculum and tools used. In contrast, some studies used post-analysis indicators, such as the study (Aldao et al., 2010) and the study (Hu et al., 2014). Previous studies have also varied in the use of research procedures in terms of tools and statistical treatment. The researcher has benefited from previous studies in several aspects, including the formulation of the study problem and its questions; in terms of results, all previous studies came out with several significant results that will benefit in discussing the current study results. The present study is consistent with previous studies in its selection of the descriptive approach and the study's goal related to knowing the level of emotional organization.

\subsubsection{Commenting on Previous Studies}

Through the previous presentation of previous studies, which were conducted on the strategies of the emotional organization, the following can be drawn: That all previous studies used measures of the emotional organization to measure the strategy of the emotional organization in general, that is, that the paragraphs were not directed to the work of the counselor, except for the study (Cook, 2009), which directed items of its scale to measure the strategies of emotional regulation in the counselor. Therefore, the researcher believes that it is necessary to identify the counselors' emotional characteristics and their relation to the counseling profession's nature and build a comprehensive study tool.

\section{The essential characteristics of the current study:}

The essential characteristic of the current study is that - within the limits of the researcher's knowledge - it is one of the rare studies that dealt with the predictive ability of emotional organization strategies for educational counselors in government schools. In light of the topic's novelty and the importance of the target group (counselors), it deals directly with counselors who are more vulnerable to various pressures, emotional and personal circumstances, and changes.

\subsection{Study Procedures}

Study methodology: The analytical description approach was used to collect and analyze data quantitatively using descriptive and inferential statistical methods to answer study questions. 


\section{The study population:}

The study population consisted of male and female educational counselors in the Capital Governorate (Amman). According to the official website of the Directorate of Education, Amman, in the first semester of the academic year 2019/2020, which numbered (529) educational counselors. As shown in Table (1):

Table 1. Study population

\begin{tabular}{|c|c|c|c|c|}
\hline Original community & $\begin{array}{l}\text { Number of } \\
\text { male } \\
\text { counselors }\end{array}$ & $\begin{array}{l}\text { Number of } \\
\text { female } \\
\text { counselors }\end{array}$ & $\begin{array}{l}\text { Total } \\
\text { number }\end{array}$ & Percentage \\
\hline $\begin{array}{l}\text { Amman Education } \\
\text { Directorate }\end{array}$ & 50 & 94 & 144 & 27.22 \\
\hline $\begin{array}{l}\text { Directorate of Education for } \\
\text { the university district }\end{array}$ & 26 & 48 & 74 & 13.99 \\
\hline $\begin{array}{l}\text { Qweismeh Education } \\
\text { Directorate }\end{array}$ & 33 & 70 & 103 & 19.47 \\
\hline $\begin{array}{l}\text { Marka District Education } \\
\text { Directorate }\end{array}$ & 66 & 103 & 169 & 31.95 \\
\hline $\begin{array}{l}\text { Wadi Al-Seer Education } \\
\text { Directorate }\end{array}$ & 23 & 16 & 39 & 7.37 \\
\hline Total & 198 & 331 & 529 & $\% 100$ \\
\hline
\end{tabular}

\section{The study sample:}

A simple random sample was chosen from all male and female educational counselors in schools affiliated with the Directorate of Education in the Capital Governorate (Amman). It constituted (20\%) of the total number of study community members from public school counselors for the academic year 2019/2020, within the experiences (10 years or less) and experience (10 years or more), the study sample consisted of (93) female and male counselors. To identify the counselors' characteristics, the members of the study sample, frequencies and percentages were found, and a table $(2,3)$ shows that:

Table 2. Distribution of study sample individuals according to gender

\begin{tabular}{lll}
\hline Gender & Number & Percentage \\
\hline Male & 41 & 44.09 \\
Female & 52 & 55.91 \\
Total & 93 & $\% 100$
\end{tabular}

Table 3. Distribution of study sample individuals according to experience

\begin{tabular}{lll}
\hline Experience & Number & Percentage \\
\hline Less than ten years & 36 & 38.71 \\
More than ten years & 57 & 61.29 \\
Total & 93 & $\% 100$ \\
\hline
\end{tabular}

\section{Study variables:}

First: independent variables, which include:

- The gender category has two levels (male, female).

- The category of experience has two levels (less than ten years, more than ten years).

Second: dependent variables: represented by the strategies of the emotional organization.

\subsection{Study Tool}

The researcher developed this scale by referring to the theoretical framework and previous studies, and after reviewing several previous scales on the emotional organization and reviewing a study (Hofmann, S. G., Carpenter, J. K., \& Curtiss, 2016), Refer to Cook's study (Cook, 2009). The study tool consisted of two parts: the first part: (a) demographic characteristics: it included (two questions) namely: 
As for the second part: it included the strategies of the emotional organization, and it had four dimensions: positive refocusing, social support, acceptance, and emotional awareness.

\subsubsection{Study Tool Validity}

1. Content Validity: The questionnaire was presented in the initial form to many arbitrators specialized in the subject. The arbitrator's agreement method was used to verify the study tool's apparent validity after preparing the scale in its initial form. The scale was presented to (8) arbitrators with specialists in the Department of Mental Health Counseling at the University of Islamic Sciences and the Department of Psychology at Mu'tah University. The observations received were adopted on the scales' dimension, and the adjustments were made accordingly, with an agreement rate of $85 \%$.

2. Construct Validity: The scale was applied to an exploratory sample consisting of (35) female and male counselors from the study community and outside its sample. Correlation coefficients were calculated on the scale and its dimensions, and Table (4) shows that:

Table 4. Correlation coefficients between the sample population scores on the scale as a whole and each dimension

\begin{tabular}{ll}
\hline Dimension & Correlation coefficients with the overall scale \\
\hline Positive refocus & $\mathbf{0 . 8 8}$ \\
social support & $\mathbf{0 . 9 0}$ \\
Acceptance & $\mathbf{0 . 9 2}$ \\
Emotional awareness & $\mathbf{0 . 8 9}$
\end{tabular}

It is clear from Table (4) that the values of the correlation coefficients between the scale dimensions in the scale as a whole are statistically significant values at the level of significance $(\alpha=0.05)$.

\subsubsection{The Reliability of the Study Tool}

The reliability of the study tool was verified in three ways: The first is the method of application and re-application, as the scale was applied to a survey sample $(n=35)$ of male and female instructors in government schools from the study community and from outside its sample, and the time lag between taking the exam and returning it (two weeks), as the stability factor $(0.82)$ is considered to be acceptable for the study. The second method, using the stability coefficient according to the Cronbach's Alpha equation for the internal consistency of the study tool's paragraphs, reached (0.92). And the third: A half-measure of the scale was performed, and the correlation coefficient between the two parts was (0.93). This percentage is considered high and acceptable for scientific research in the humanities.

\section{How to correct the scale}

It refers to placing the degree of the subject's answer on each of the scale's items and then adding the degrees to find the degree on each dimension of the scale and the overall degree. The answers of the scale axis items were classified in the second part of the study tool according to Likert's five-digit ranking, and five answers determined it according to their digital weight and according to the degree of approval as follows: (Strongly Agree -5), (Agree, 4 ), (Neutral, 3), (Disagree, 2), (Strongly disagree, 1). The scaling arithmetic mean was also relied upon as follows: From 1- 1.49 I do not strongly agree, $1.5-2.49$ as I disagree, and from $2.5-$ to 3.49 as neutral, and from $3.5-4.49$ as agree, and more than 4.49 as strongly agree, According to the degree of the general direction of the element, the gradient was converted into a triple to give a closer and more precise picture of reality as follows: from 1 to 2.49 a weak general direction, from 2.50 to 3.49 Moderate Direction, 3.50 to 5 High or Strong Direction. Noting that all items of all elements are handled to match one gradient and turning the positive items into negative ones to get the general direction, where the positive items $(1,2,3,20,19,17,16,11$, $10,9,8,7,6,5,4)$ the negative items $(15,14,13,12)$. The highest score obtained by the examiner by answering all the paragraphs in the scale is $(20 * 5=100)$, and the lowest degree is $(20 * 1=20)$, where it is limited to (20-100) Degree The scale may include four dimensions:

1) The dimension related to positive refocusing, included (5 paragraphs) as follows: I focus on the positive aspects of the solution that I tend to see, looking at problems as a natural thing in a person's life, reacting naturally when I go through troublesome situations, thinking things more beautifully than I experienced them, feeling satisfied with my performance in different conditions.

2) The second dimension relates to social support, and it included (5 paragraphs): I feel better when I know how others deal with their emotions, it helps me listen to someone else's thoughts on how to deal with things when I feel anxious, I like being in the presence of others and sharing my joy because it increases the 
right feeling. I want to be with people who sympathize with me when I feel bad; I want to be always with positive people most of the time.

3) The third dimension: Relates to receptivity, and it included (5 items): I think I cannot change the events around me. Living with what is happening around me reduces stress and anxiety. I am annoyed at my inability to change reality. I am negatively affected when I find that the conditions are more vital than me. I find it natural to feel angry from time to time.

4) The fourth dimension: relates to emotional awareness, and it included (5 paragraphs), which are: I understand my feelings in most situations, I want to pay more attention to what I feel, I must express my feelings when I am angry, I think my feelings are correct and appropriate to the situations that I am going through, I must distinguish between the nature of my different emotions.

\section{Statistical Treatment}

To answer the study's questions, empty the responses, and extract the results, a program (SPSS) was used to process the data statistically, as the following statistical processes were used:

- Arithmetic averages and standard deviations

- T-test

\section{Presentation and Discussion of Results}

Results related to the first question: What is the level of emotional organization among educational counselors in the dimensions (positive refocusing, social support, acceptance, and emotional awareness) from the point of view of the study sample?

Arithmetic averages and standard deviations for the responses of the educational counselors were calculated to answer this question on the level of the effect of the dimensions of the scale (positive refocusing, social support, acceptance, and emotional awareness in the emotional organization of the counselors as follows:

Table 5. Arithmetic averages and standard deviations for the dimension of positive refocus

\begin{tabular}{lllll}
\hline Item N. & Item & Mean & Standard deviation & Level \\
1 & Focus on the positive aspects of the solution I tend to & 3.06 & 1.389 & Moderate \\
2 & I look at problems as a natural thing in human life & 3.06 & 1.451 & Moderate \\
3 & $\begin{array}{l}\text { Get excited naturally when going through annoying } \\
\text { situations }\end{array}$ & 3.08 & 1.408 & Moderate \\
& $\begin{array}{l}\text { I think things are more beautiful than I experienced } \\
4\end{array}$ & 3.09 & 1.373 & Moderate \\
5 & $\begin{array}{l}\text { I am satisfied with my performance in different } \\
\text { situations }\end{array}$ & 3.08 & 1.345 & Moderate \\
& & 3.07 & 1.375 & Moderate \\
\hline
\end{tabular}

Based on the results of Table (5), it is clear that the general level of the counselors' responses to the level of emotional organization in the dimension of positive refocusing came at a moderate degree, and the general mathematical average reached (3.07) with a standard deviation (1.375), Most of the paragraphs in Table (5) came with intermediate estimates. Item (4) came first with an arithmetic mean (3.09) and a standard deviation (1.373), while paragraph (1) came in the last rank with average arithmetic (3.06) and a standard deviation (1.389); most of the items in Table (5) came with intermediate estimates. Paragraph No. (4) came first with an arithmetic mean (3.09) and a standard deviation (1.373). In contrast, item (1) came in the last rank with average arithmetic (3.06) and a standard deviation (1.389), and the appearance of this result in the general awareness of the counselors explains the importance of interpreting the situations they are going through in a better and more positive way than it is in reality. Therefore, as a way of positive emotional organization, attitudes and pressures of life in general, and forces of professional guidance work, this is consistent with a study (Cook, 2009) that confirms that counselors tend to interpret situations positively and thus have the ability to organize emotions better over time. 
Table 6. Means and standard deviations for the social support dimension

\begin{tabular}{lllll}
\hline Item N. & Item & Mean & Standard deviation & Level \\
\hline 6 & $\begin{array}{l}\text { I feel better when I know how others relate to their } \\
\text { emotions. }\end{array}$ & 3.33 & 1.492 & Moderate \\
7 & $\begin{array}{l}\text { It helps me listen to someone else's thoughts on how } \\
\text { to handle things when I'm worried. }\end{array}$ & 3.10 & 1.490 & Moderate \\
& $\begin{array}{l}\text { I love being in the presence of others and sharing } \\
\text { my joy because it increases the good feeling. }\end{array}$ & 3.09 & 1.464 & Moderate \\
9 & $\begin{array}{l}\text { I would like to be with people who sympathize with } \\
\text { me when I feel bad }\end{array}$ & 3.35 & 1.464 & Moderate \\
10 & $\begin{array}{l}\text { I want to be in constant contact with positive people } \\
\text { most of the time }\end{array}$ & 3.20 & 1.508 & Moderate \\
General Arithmetic average & 3.22 & 1.466 & Moderate \\
\hline
\end{tabular}

Based on the results of Table (6), it is clear that the general level of the responses of the counselors on the level of the emotional organization came at a moderate degree, and the general mean score was 3.22 with a standard deviation of 1.466, most of the paragraphs in Table (6) came with intermediate estimates. Item (9) came first with an average of (3.35) and a standard deviation (1.464). At the same time, item (8) came in the last rank with a mean (3.09) and standard deviation (1.464). The appearance of this result explains that the counselors tend to form social relationships with people who provide positive social support continuously to help them increase stamina to cope with emotional exhaustion, and this is what (Gunduz, 2012) referred to in his study titled The Relationship between Psychological Burning and Self-Efficiency Among School Counselors.

The level of emotional fatigue was studied as a factor of psychological burning and linked to social support. The study indicated that counselors who receive social support have a positive attitude towards their profession and can organize their emotions in general.

Table 7. Means and the standard deviations for the acceptance dimension

\begin{tabular}{lllll}
\hline Item N. & Item & Mean & Standard deviation & Level \\
\hline 11 & I think that I cannot change events around me. & 4.18 & 1.215 & Moderate \\
12 & $\begin{array}{l}\text { Living with what is happening around me reduces } \\
\text { stress and anxiety }\end{array}$ & 3.80 & 1.471 & Moderate \\
13 & I find it normal to feel angry from time to time & 4.29 & 1.157 & Moderate \\
14 & $\begin{array}{l}\text { I am negatively affected when I find that the } \\
\text { conditions are more robust than me }\end{array}$ & 3.26 & 1.169 & Moderate \\
15 & I am annoyed that I cannot change reality & 4.08 & 1.265 & Moderate \\
General Arithmetic average & & & Moderate \\
\hline
\end{tabular}

Based on the results of Table (7), it is clear that the general level of the responses of the counselors on the level of the emotional organization came in a high degree, and the general arithmetic average reached 4.08 with a standard deviation of 1.265, and most of the paragraphs in Table (7) came with high estimates. Paragraph No. (13) came first with an average of (4.29) and a standard deviation of (1.157). At the same time, item (12) ranked last with an average mean of (3.80) and a standard deviation of (1.471).

The appearance of this result explains that counselors experience many emotions and emotions, such as feelings of guilt, anger, and anxiety, and this is what (2018 Prikhidko, Swank,) referred to as the counselor begins to realize that it is natural for him to feel anger from time to time and that the expression of anger must take socially acceptable forms in the framework of his work as a counselor. 
Table 8. Means and standard deviations for the emotional awareness dimension

\begin{tabular}{lllll}
\hline Item N. & Item & Mean & Standard deviation & Level \\
\hline 16 & I have to express my feelings when I am angry. & 3.43 & 1.528 & Moderate \\
17 & I want to pay more attention to what I feel. & 3.61 & 1.460 & High \\
18 & I Realize my feelings in most situations & 3.68 & 1.431 & High \\
19 & $\begin{array}{l}\text { I think my feelings are correct and appropriate to the } \\
\text { situations I am going through }\end{array}$ & 3.38 & 1.546 & Moderate \\
20 & $\begin{array}{l}\text { I must distinguish between the nature of my different } \\
\text { emotions }\end{array}$ & 3.51 & 1.479 & High \\
\multicolumn{2}{l}{ General Arithmetic average } & 3.52 & 1.472 &
\end{tabular}

Based on the results of Table (8), it is clear that the general level of the counselors' responses to the level of the emotional organization came in a high degree, and the general arithmetic average reached 3.52 with a standard deviation of 1.472, and most of the paragraphs in Table (8) came with high estimates. Except for items $(16,19)$, it came with an average estimation, and item (18) came first with an average of (3.68) and a standard deviation of (1.431). At the same time, item (16) ranked last with an average mean (3.43) and a standard deviation (1.528). These results explain that the counselor reaches an advanced stage as a specialist in his psychology and professional studies in psychological and educational guidance to recognize the nature of emotions and feelings he experiences daily in different situations and people; this comes in favor of the counselor in terms of mental health for him and in terms of practice as a counselor as mentioned (Al-Sharifain Saad, 2015).

Table 9. Means and standard deviations for scale dimensions

\begin{tabular}{llll}
\hline Dimension & N & Mean & Standard deviation \\
\hline Mean of the first dimension & 93 & 3.07 & 1.375 \\
Mean of the second dimension & 93 & 3.22 & 1.466 \\
Mean of the third dimension & 93 & 4.08 & 1.265 \\
Mean of the fourth dimension & 93 & 3.52 & 1.472
\end{tabular}

From reading Table (9), we note that the third dimension came first with an arithmetic average of (4.08) and standard deviation of (1.265), while the fourth dimension came second with an arithmetic mean of (3.52) and standard deviation of (1.472). The second dimension came in the third position with an average mean (3.22) and a standard deviation (1.466) whereas, the first dimension ranked last with a mean (3.07) and a standard deviation (1.375).

\subsection{Results Related to the Second Question}

Are there statistically significant differences at the significance level $(0.05)$ in the average degree of emotional organization among school counselors in Amman's capital city due to the gender variable (male, female)?

Arithmetic averages and standard deviations for the counselors' answers were calculated to answer this question, according to the gender variable (male, female), and Table (10) shows these results:

Table 10. T-Test according to the gender variable

\begin{tabular}{lllllll}
\hline variable & Number & $\begin{array}{l}\text { Arithmetic } \\
\text { mean }\end{array}$ & $\begin{array}{l}\text { standard } \\
\text { deviation }\end{array}$ & $\begin{array}{l}\text { Value of } \\
\mathbf{t}\end{array}$ & $\begin{array}{l}\text { Degrees of } \\
\text { freedom }\end{array}$ & $\begin{array}{l}\text { Statistical } \\
\text { significance }\end{array}$ \\
\hline Male & 41 & 94.39 & 7.28 & $\mathbf{1 3 . 7 2 0}$ & $\mathbf{9 1}$ & $\mathbf{0 . 0 0 0}$ \\
Female & 52 & 49.78 & 19.766 & & & \\
\hline
\end{tabular}

Based on the results shown in the above Table, we note that the differences between male and female answers were statistically significant and in favor of males with an average score of (94.39) and a standard deviation of (7.28). While the average of female grades was (49.78), and a standard deviation was (19.766), these results explain that females' psychological characteristics are illustrated by their tendency to employ emotions in shaping social relations. Consequently, they continuously exhaust their psychological and emotional energies, which affects the use and employment of emotional organization strategies appropriately compared to males. These results appear normal in light of what the Archer study 2019 went through; these results were consistent with the study (Kwon et al., 2013), which dealt with the relationship between emotion regulation strategies and 
depressive symptoms among college students within the gender and culture variable. The results were that the differences were in favor of males over females in terms of the levels of depression in females; it is related to the employment of specific emotional regulation processes, such as rumination and suppression than others.

The third question: Are there statistically significant differences at the level of significance $(0.05)$ in the average degree of emotional organization among school counselors in the capital city Amman due to the variable number of years of experience (less than ten years, more than ten years)?

Arithmetic averages and standard deviations for the counselors' answers were calculated to answer this question, according to the variable of years of experience (less than ten years, more than ten years), and Table (5) shows these results:

Table 11. T-Test according to the number of years of experience variable

\begin{tabular}{lllllll}
\hline Variable & Number & Mean & $\begin{array}{l}\text { standard } \\
\text { deviation }\end{array}$ & $\begin{array}{l}\text { Value of } \\
\text { "t" }\end{array}$ & $\begin{array}{l}\text { Degrees of } \\
\text { freedom }\end{array}$ & Sig \\
\hline $\begin{array}{l}\text { Less than ten } \\
\text { years }\end{array}$ & 36 & 52.42 & 20.72 & 12.483 & 91 & 0.000 \\
$\begin{array}{l}\text { More than ten } \\
\text { years }\end{array}$ & 57 & 96.39 & 5.06 & & & \\
\hline
\end{tabular}

Based on the results shown in the above table, we note that the differences between the answers of the counselors were statistically significant, and for the benefit of the counselors with more than ten years of experience with an average score of (96.39), the standard deviation was (5.06). Whereas the average score of experienced counselors was less than ten years (52.42), and a standard deviation was (20.72), this result is explained by the fact that years of experience are represented by working for many years in counseling and guidance, whether in schools or psychological centers, and exposure to experiences. And opportunities to join extension training courses make a difference for counselors working in the field for more than ten years, and we find that (Cook, 2009) in a study pointed to the same result in that the counselors are increasing their organizational ability in employing the appropriate emotional organization strategies through training and experience.

\section{Recommendations}

In light of the results, the researcher recommends:

1) There is a necessity of preparing supervisory training programs for school counselors to raise their emotional organization levels, which helps the counselor to be able to employ the strategies of the emotional organization effectively.

2) There is a necessity to conduct more studies to learn about the nature and size of psychological and social pressures resulting from working in the counseling profession and its impact on the counselor's emotional organization processes.

3) To carry out an evaluation study of the level of emotional organization strategies periodically for the counselors, it helps reveal the level of emotional organization and then work to strengthen the strengths and modify the weaknesses.

4) To apply the scale of emotional organization strategies in the rest of the governorates in the Kingdom to see the levels of emotional organization strategies in the presence of additional variables.

\section{References}

Abel, H., Abel, A., \& Smith, R. L. (2012). The effects of a stress management course on counselors-in-training. Counselor Education and Supervision, 51, 64-78. https://doi.org/10.1002/j.1556-6978.2012.00005.x

Abu Hammad, Nasser. (2006). Counselor to the educational counselor: a field counselor. Oman: the modern world of books.

Afaneh, Mohamed. (2018). Emotional organization and its relationship to life satisfaction among students of Palestinian universities in Gaza Governorate. Master Thesis, College of Education - Islamic University of Gaza.

Aldao, A., Nolen-Hoeksema, S., \& Schweizer, S. (2010). Emotion-regulation strategies across psychopathology: A meta-analytic review. Clinical psychology review, 30(2), 217-237. https://doi.org/10.1016/j.cpr.2009.11.004 
Alsharyfyn, \& Ahmed Saad, Murad. (2015). Introduction to psychological counseling from an artistic and scientific perspective. Dar Al-Fikr. Amman, Jordan.

Al-Zuhaimi, Assaf. (2011). Study the differences in emotional intelligence among open education students at Damascus University, according to some variables. Damascus University Journal, 27(3), 233-278.

Archer, J. (2019). The reality and evolutionary significance of human psychological sex differences. Biological Reviews, 94, 1381-1415. https://doi.org/10.1111/brv.12507

Arndt, J. E., \& Fujiwara, E. (2014). Interactions Between Emotion Regulation and Mental Health. Austin J Psychiatry BehavSci, 1(5), 1021.

Berking, M., \& Whitley, B. (2014). Affect regulation training: a practitioners' manual. Berlin: Springer. https://doi.org/10.1007/978-1-4939-1022-9

Berking, M., \& Wupperman, P. (2012). Emotion regulation and mental health: recent findings, current challenges, and future directions. Current Opinion in Psychiatry, 25(2), 128-134. https://doi.org/10.1097/YCO.0b013e3283503669

Cole, P. M., Martin, S. E., \& Dennis, T. A. (2004). Emotion regulation as a scientific construct: Methodological challenges and directions for child development research. Child Development, 75(2), 317-333. https://doi.org/10.1111/j.1467-8624.2004.00673.x

Cook, J. D. (2009). Emotion regulation for counselors-in-training: Determining and developing applicants and trainees' emotional suitability for counseling work (Unpublished doctoral dissertation). Oregon State University, Corvallis.

Eisenberg, N. (2001). The core and correlates of affective, social competence. Social Development, 10, 120-124. https://doi.org/10.1111/1467-9507.00151

Golman, D. (1999). The emotionally intelligent worker. Futurist, 33(3), 14-19.

Gratz, K. L., \& Roemer, L. (2004). Multidimensional assessment of emotion regulation and deregulation: Development, factor structure, and initial validation of the difficulties in emotion regulation scale. Journal of psychopathology and behavioral assessment, 26(1), 41-54. https://doi.org/10.1023/B:JOBA.0000007455.08539.94

Greenberg, L. (2004). Emotion-focused therapy. Clinical Psychology and Psychotherapy, 11, 3-16. https://doi.org/10.1002/cpp.388

Gross, J. J. (2002). Emotion regulation: Affective, cognitive, and social consequences. Psychophysiology, 39, 281-291. https://doi.org/10.1017/S0048577201393198

Gross, J. J., \& Barrett, L. F. (2011). Emotion generation and emotion regulation: One or two depends on your perspective. Emotion Review, 3, 8-16. https://doi.org/10.1177/1754073910380974

Gunduz, Bulent. (2012). Self-Efficacy and Burnout in Professional School Counselors, Educational. Sciences: Theory and Practice, 12(3), 1761-1767.

Hofer, M. A. (2006). Psychobiological roots of early attachment. Current Directions in Psychological Science, 15, 84-88. https://doi.org/10.1111/j.0963-7214.2006.00412.x

Hofmann, S. G. (2014). Interpersonal emotion regulation model of mood and anxiety disorders. Cognitive Therapy and Research, 38, 483-492. https://doi.org/10.1007/s10608-014-9620-1

Hu, T., Zhang, D., Wang, J., Mistry, R., Ran, G., \& Wang, X. (2014). The relation between emotion regulation and mental health: a meta-analysis review. Psychological Reports, 114(2), 341-362. https://doi.org/10.2466/03.20.PR0.114k22w4

Koole, S. L. (2009). The psychology of emotion regulation: An integrative review. Cognition and Emotion, 23(1), 4-41. https://doi.org/10.1080/02699930802619031

Kwon, H., Yoon, K. L., Joormann, J., \& Kwon, J. H. (2013). Cultural and gender differences in emotion regulation: Relation to depression. Cognition \& emotion, 27(5), 769-782. https://doi.org/10.1080/02699931.2013.792244

Mauss, I. B., Bunge, S. A., \& Gross, J. J. (2007). Automatic emotion regulation. Social and Personality Psychology Compass, 1(1), 146-147. https://doi.org/10.1111/j.1751-9004.2007.00005.x 
Parker, S., \& Thomas, R. (2009). Psychological differences in shame vs. guilt: Implications for mental health counselors. Journal of Mental Health Counseling, 31, 213-224. https://doi.org/10.17744/mehc.31.3.f405217281988832

Prikhidko, A., Su, Y.-W., \& Houseknecht, A. (2017). Emotion regulation for counselors-in-training: Grounded theory. Manuscript in preparation.

Prikhidko, A., Su, Y.-W., \& Houseknecht, A. (2018). Emotion Regulation for Counselors. Journal of Counseling \& Development, 96(2), 206-212. Wiley Online Library. https://doi.org/10.1002/jcad.12193

Quoidbach, J., Berry, E. V., Hansenne, M., \& Mikolajczak, M. (2010). Positive emotion regulation and well-being: Comparing the impact of eight savoring and dampening strategies. Personality and Individual Differences, 49, 368-373. https://doi.org/10.1016/j.paid.2010.03.048

Salloum, Hana. (2015). Emotional organization strategies and their relationship to problem-solving "A comparative study on a sample of high school and undergraduate students in Damascus." Master Thesis, College of Education - Damascus University.

Scherer, K. R. (2005). What are emotions? And how can they be measured? Social Science Information, 44, 695-729. https://doi.org/10.1177/0539018405058216

Stoltenberg, C. D., \& McNeill, B. W. (2009). IDM supervision: An integrative developmental model for supervising counselors and therapists. New York, NY: Taylor \& Francis.

\section{Copyrights}

Copyright for this article is retained by the author(s), with first publication rights granted to the journal.

This is an open-access article distributed under the terms and conditions of the Creative Commons Attribution license (http://creativecommons.org/licenses/by/4.0/). 